\title{
Forecasting California's Earthquakes-What Can We Expect in the Next 30 Years?
}

Tn a new comprehensive study,
scientists have determined that the
chance of having one or more magni-
tude 6.7 or larger earthquakes in the
California area over the next 30 years is
greater than $99 \%$. Such quakes can be
deadly, as shown by the 1989 magnitude
6.9 Loma Prieta and the 1994 magnitude
6.7 Northridge earthquakes. The likeli-
hood of at least one even more powerful
quake of magnitude 7.5 or greater in the
next 30 years is $46 \%-$ such a quake is
most likely to occur in the southern half
of the State. Building codes, earthquake
insurance, and emergency planning
will be affected by these new results,
which highlight the urgency to prepare
now for the powerful quakes that are
inevitable in California's future.

\section{What Is an Earthquake Rupture Forecast?}

Californians know that their State is subject to frequent-and sometimes very destructive-earthquakes. Accurate forecasts of the likelihood of quakes can help people prepare for these inevitable events. Because scientists cannot yet make precise predictions of the date, time, and place of future quakes, forecasts are in the form of the probabilities that quakes of certain sizes will occur during specified periods of time.

In our daily lives, we are used to making decisions based on probabilities - from weather forecasts (such as a $30 \%$ chance of rain) to the annual chance of being killed by lightning (about $0.0003 \%$ ). Similarly, earthquake probabilities derived by scientists can help us plan and prepare for future quakes.

Earthquake forecasts for California have been developed in the past by multidisciplinary groups of scientists and engineers, each known as a "Working Group on California Earthquake Probabilities" (WGCEP 1988, 1990, 1995, 2003). However, those forecasts were limited to particular regions of California. Because of this, WGCEP 2007 was commissioned to develop an updated, statewide forecast, the latest result of which is the Uniform California

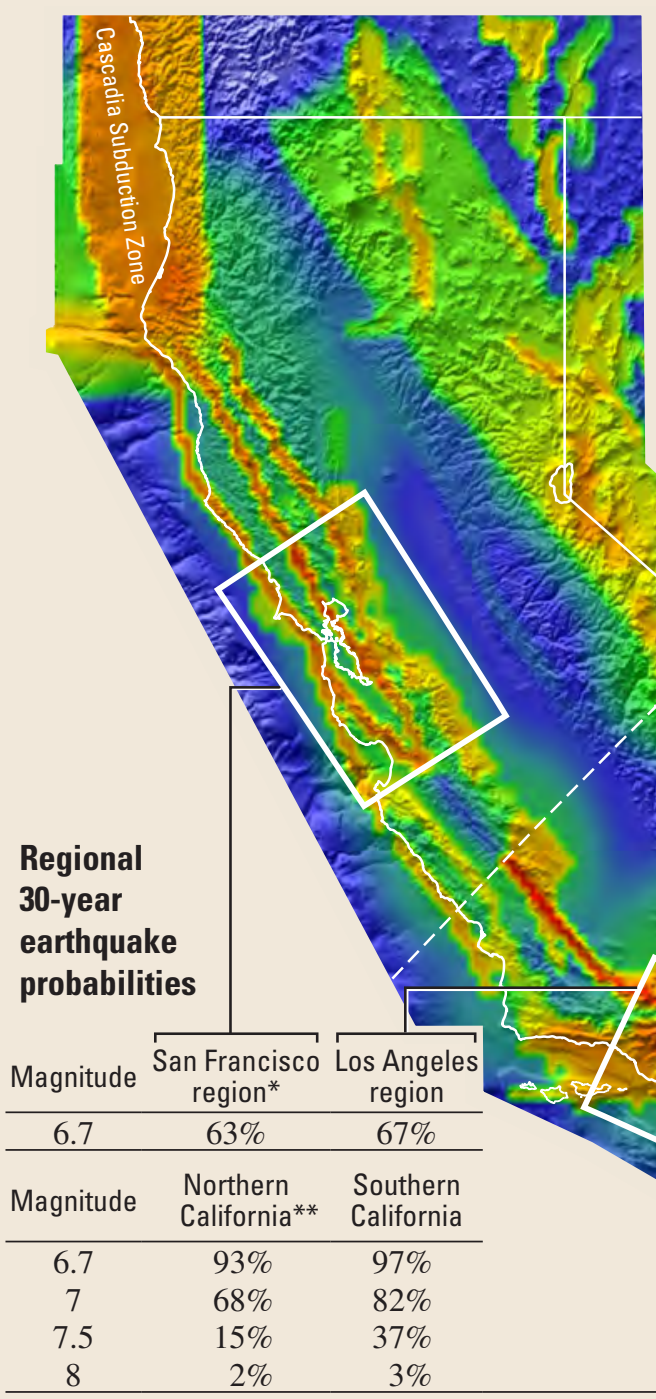

\section{CALIFORNIA AREA EARTHOUAKE PROBABILITY More than $99 \%$}

probability in the next 30 years for one or more magnitude 6.7 or greater quake capable of causing extensive damage and loss of life. The map shows the distribution throughout the State of the likelihood of having a nearby earthquake rupture (within 3 or 4 miles).

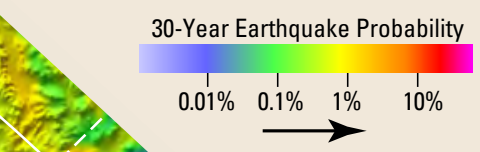

Probabilities from UCERF for the San Francisco region are nearly identical to the previous results from WGCEP 2003.

**These probabilities do not include the Cascadia Subduction Zone

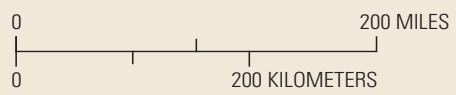

Earthquake Rupture Forecast, Version 2, or "UCERF" (U.S. Geological Survey (USGS) Open-File Report 2007-1437, http://pubs.usgs. gov/of/2007/14377). Organizations sponsoring WGCEP 2007 include the USGS, California Geological Survey, and the Southern California Earthquake Center. The comprehensive new forecast builds on previous studies and also incorporates abundant new data and improved scientific understanding of earthquakes.

When an earthquake occurs, two things happen - a fault ruptures (a crack in the Earth's crust gives way and slips under tectonic pressure) and seismic waves, caused by this sudden fault motion, radiate out like ripples from a pebble tossed into a pond. The shaking that occurs as seismic waves pass by causes most quake damage. The strength of the waves depends partly on the quake's magnitude, which is a function of the size of the fault that moves and the amount of slip.

The UCERF study's goal was to determine probabilities for different parts of California of earthquake ruptures of various magnitudes, but not to estimate the likelihood of shaking ("seismic hazard") that will be caused by these quakes. This distinction is important, because even areas in the State with a low probability of fault rupture can experience shaking and damage from distant, powerful quakes. 


\section{How Did Scientists Make This Forecast?}

California sits on the boundary between two of the Earth's major tectonic plates-the Pacific and North American Plates - which move inexorably past each other at a rate of about 2 inches per year. Much of this motion is accommodated from time to time by sudden slip on faults, producing earthquakes. Although the San Andreas Fault is the main locus of slip, hundreds, if not thousands, of other faults splay out from the plate boundary, spreading the threat of large earthquake ruptures through most of the State.

T he new Uniform California Earthquake Rupture Forecast (UCERF) combines information from geodesy (precise data on the slow relative movement of the Earth's tectonic plates), geology (mapped locations of faults and documented offsets on them), seismology (occurrence patterns of past earthquakes), and paleoseismology (data from trenches across faults documenting the dates and offsets of past earthquakes on them). The first three kinds of data are shown here as layers in the diagram. All four kinds of data are combined mathematically to produce the final probability values for future ruptures in the California area, in regions of the State, and on individual faults.

Building on several previous studies and decades of data collection, UCERF was developed by a multidisciplinary group of scientists and engineers, known as the 2007 Working Group on California Earthquake Probabilities. Advice and comment was sought regularly from the broader community of earthquake scientists and engineers through open meetings and workshops. Where experts disagreed on aspects of the forecast, alternative options were accounted for in calculations to reflect these uncertainties. The final forecast is a sophisticated integration of scientific fact and expert opinion.

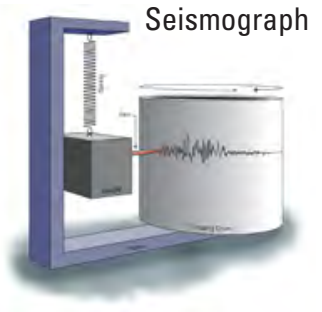

\section{Seismology}

Monitoring instruments provide å record of California earthquakes during recent historical times-where and when they occur and how strong they are

\section{Geology}

Geologic field mapping and aerial photos trace out California's many faults and document the accumulated slip in earthquakes over thousands of years. Color spectrum shows rates of slip, from fast (purple and red) to very slow (dark blue).

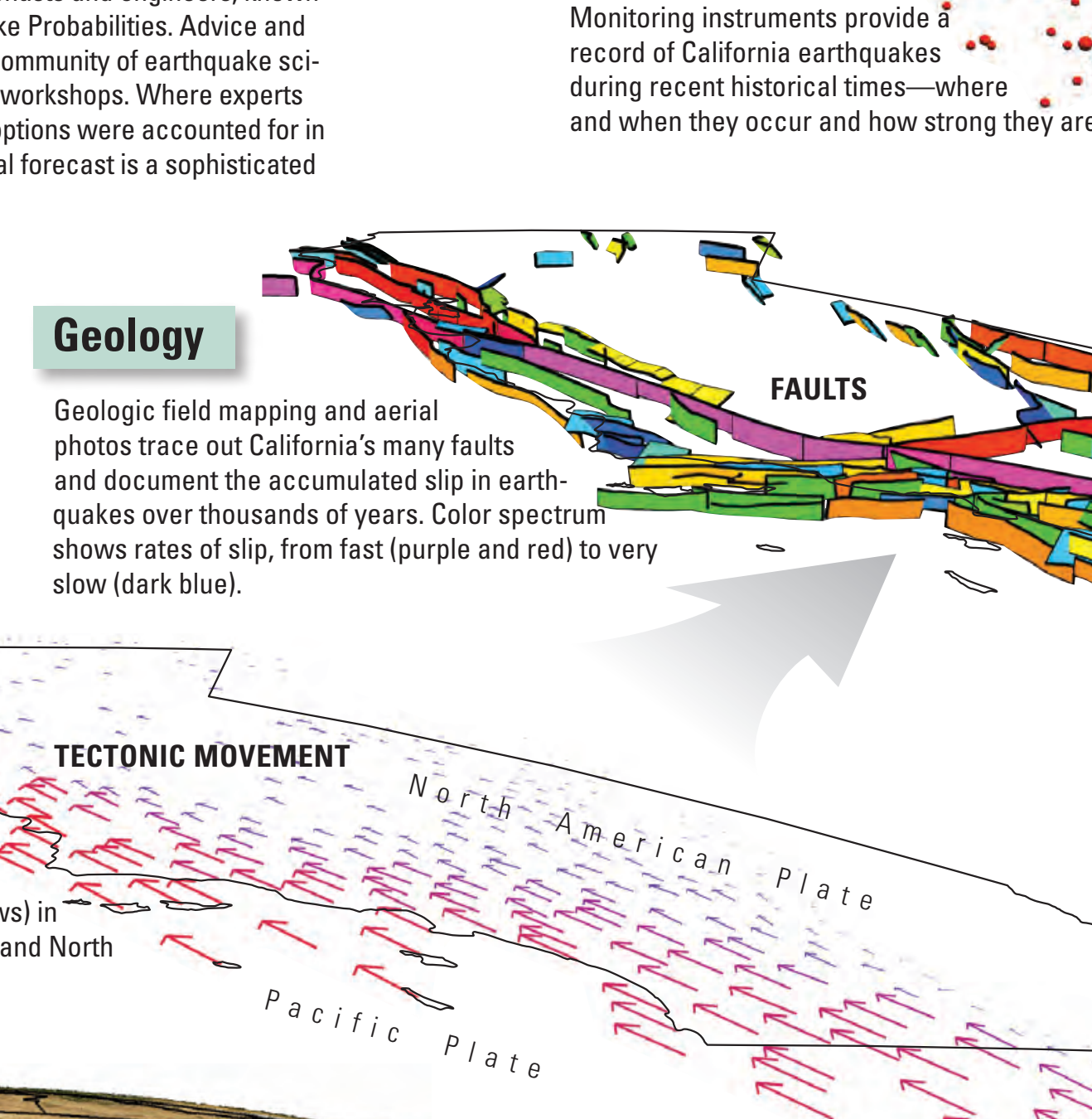

\section{Geodesy}

Global positioning system (GPS) observations by satellite document how fast various points in California are moving (arrows) in response to the steady motion of the Pacific and North American tectonic plates.
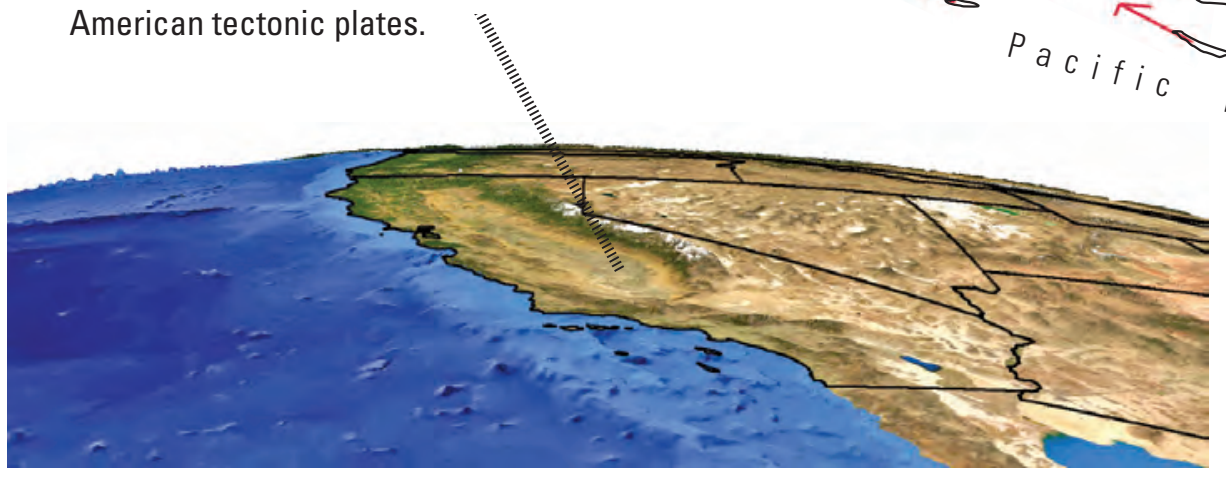

$$
\text { Pla te }
$$




\section{How Likely is a Damaging Quake in the Next 30 Years?}

California straddles the boundary between two of the Earth's tectonic plates — as a result, it is broken by numerous earthquake faults. Taking into account the earthquake histories and relative rates of motion on these many faults, the UCERF study concludes that there is a probability of more than $99 \%$ that in the next 30 years Californians will experience one or more magnitude 6.7 or greater quakes, potentially capable of causing extensive damage and loss of life. For powerful quakes of magnitude 7.5 or greater, there is a $46 \%$ chance of one or more in the next 30 years - such a quake is twice as likely to occur (37\%) in the southern half of the State than in the northern half $(15 \%)$.

Smaller magnitude earthquakes are more frequent than larger quakes. According to the new forecast, about 3 magnitude 5 or greater quakes will occur in the California region per year, and a magnitude 6 or greater quake about every 1.5 years. These numbers do not include aftershocks that follow larger quakes-including them would roughly double the expected number of magnitude 5 or greater quakes.

\section{STATEWIDE EARTHOUAKE PROBABILITIES}

The numbers represent current best estimates. As earthquake science progresses, these probabilities will change. Actual repeat times vary considerably and only rarely will be exactly as listed in the table.

\begin{tabular}{c|c|c}
\hline Magnitude & $\begin{array}{c}30 \text {-year probability of } \\
\text { one or more events } \\
\text { greater than or equal } \\
\text { to the magnitude }\end{array}$ & $\begin{array}{c}\text { Average } \\
\text { repeat } \\
\text { time } \\
\text { (years) }\end{array}$ \\
\hline 6.7 & $>99 \%$ & 5 \\
7 & $94 \%$ & 11 \\
7.5 & $46 \%$ & 48 \\
8 & $4 \%$ & 650 \\
\hline
\end{tabular}

*Not including Cascadia Subduction Zone

For the entire California region, the fault with the highest probability of generating at least one magnitude 6.7 or larger earthquake is the southern San Andreas (59\% in the next 30 years). For northern California, the most likely source of such a quake is the Hayward-Rodgers Creek Fault (31\% in next 30 years) - see USGS Fact Sheet 2008-3019. Quake probabilities for many parts of the State are similar to those in previous studies, but the new probabilities for the Elsinore and San Jacinto Faults in southern California are about half those previously determined. For the far northwestern part of the State, a major source of quakes is the offshore 750-mile-long "Cascadia Subduction Zone," which extends south about 150 miles into California. For the next 30 years there is a $10 \%$ probability of a magnitude 8 to 9 quake somewhere along the zone-such quakes occur about every 500 years.

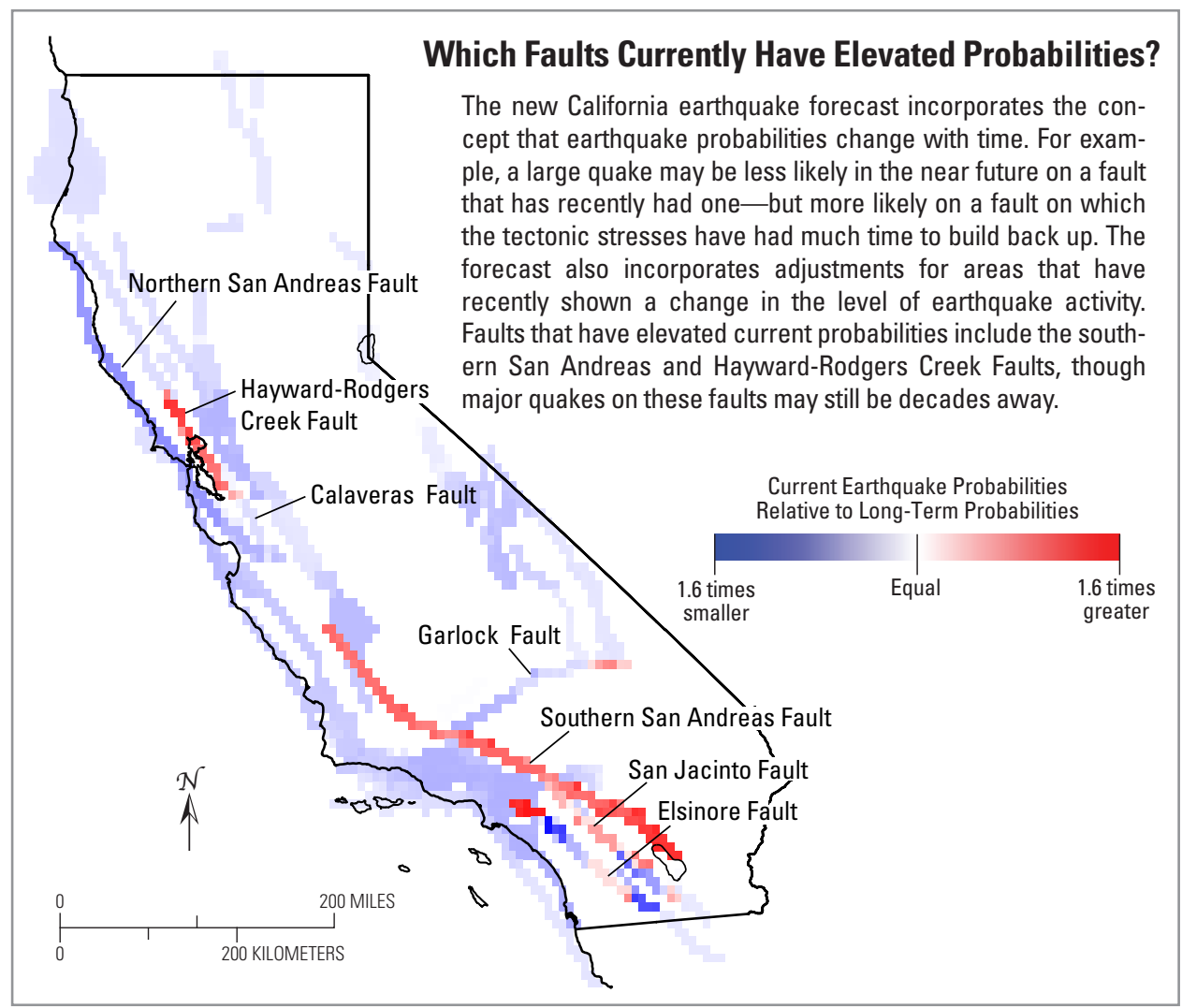

The UCERF forecast was evaluated by an independent scientific review panel, as well as by both the California and National Earthquake Prediction Evaluation Councils, making it one of the most extensively reviewed earthquake forecasts ever produced. Uncertainties remain because the new quake probabilities are the result of evaluating and accommodating several earthquake theories. As scientific understanding of quakes improves, the probabilities will change.

The results of the UCERF study are a reminder that all Californians live in earthquake country and should therefore be prepared (see Putting Down Roots in Earthquake Country at http://www.earthquakecountry.info/roots-). The

\section{INDIVIDUAL FAULT PROBABILITIES}

The UCERF report assigns individual probabilities to specific known major faults. Below are 30 -year probabilities for seven of the faults for which scientists have the most data. Many other faults also have significant probabilities - in fact, the next big quake in California is just as likely to occur on one of the other faults in the State.

\begin{tabular}{l|c}
\hline \multicolumn{1}{c|}{ Fault } & $\begin{array}{c}\text { Probability of one or } \\
\text { more magnitude } 6.7 \\
\text { or greater quake }\end{array}$ \\
\hline Southern San Andreas & $59 \%$ \\
Hayward-Rodgers Creek & $31 \%$ \\
San Jacinto & $31 \%$ \\
Northern San Andreas & $21 \%$ \\
Elsinore & $11 \%$ \\
Calaveras & $7 \%$ \\
Garlock & $6 \%$
\end{tabular}

USGS has already used the UCERF to estimate California's seismic hazard, which in turn will be used to update building codes. Other subsequent studies will add information on the vulnerability of manmade structures to estimate expected losses ("seismic risk"). In these ways, UCERF will help to increase public safety and community resilience to earthquake hazards.

Earthquakes cannot be prevented, but the damage they do can be greatly reduced through prudent planning and preparedness. The ongoing work of USGS, California Geological Survey, Southern California Earthquake Center, and other scientists in evaluating quake probabilities is part of the National Earthquake Hazard Reduction Program's efforts to safeguard lives and property from the future quakes that are certain to strike in California and elsewhere in our Nation.

\section{Edward H. Field, Kevin R. Milner, and the 2007 Working Group on California Earthquake Probabilities}

Edited by Peter H. Stauffer and James W. Hendley II Layout by David R. Jones

COOPERATING ORGANIZATIONS

Southern California Earthquake Center (SCEC) California Geological Survey (CGS) California Earthquake Authority

For more information contact:

Earthquake Information Hotline (650) 329-4085 U.S. Geological Survey, Mail Stop 977 345 Middlefield Road, Menlo Park, CA 94025 http://earthquake.usgs.gov/ http://www.scec.org

This Fact Sheet and any updates to it are available online at http://pubs.usgs.gov/fs/2008/3027 